BMJ Open

Respiratory

Research

\title{
Identifying the challenges and facilitators of implementing a COPD care bundle
}

\author{
Laura Lennox, ${ }^{1}$ Stuart Green, ${ }^{1}$ Cathy Howe, ${ }^{1}$ Hannah Musgrave, ${ }^{1}$ Derek Bell, ${ }^{1}$ \\ Sarah Elkin ${ }^{2}$
}

To cite: Lennox L, Green S, Howe $\mathrm{C}$, et al. Identifying the challenges and facilitators of implementing a COPD care bundle. BMJ Open Resp Res 2014:1:e000035.

doi:10.1136/bmjresp-2014000035

Received 21 March 2014 Revised 2 June 2014 Accepted 3 June 2014

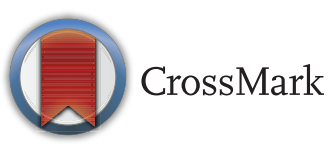

${ }^{1}$ Department of Medicine, Imperial College London, NIHR CLAHRC for Northwest London, London, UK ${ }^{2}$ Imperial College NHS Trust, St Mary's Hospital, London, UK

Correspondence to Laura Lennox; I.lennox@imperial.ac.uk

\section{ABSTRACT}

Background: Care bundles have been shown to improve outcomes, reduce hospital readmissions and reduce length of hospital stay; therefore increasing the speed of uptake and delivery of care bundles should be a priority in order to deliver more timely improvements and consistent high-quality care. Previous studies have detailed the difficulties of obtaining full compliance to bundle elements but few have described the underlying reasons for this. In order to improve future implementation this paper investigates the challenges encountered by clinical teams implementing a chronic obstructive pulmonary disease (COPD) care bundle and describes actions taken to overcome these challenges. Methods: An initial retrospective documentary analysis of data from seven clinical implementation teams was undertaken to review the challenges faced by the clinical teams. Three focus groups with healthcare professionals and managers explored solutions to these challenges developed during the project.

Results: Documentary analysis identified 28 challenges which directly impacted implementation of the COPD care bundle within five themes; staffing, infrastructure, process, use of improvement methodology and patient and public involvement. Focus groups revealed that the five most significant challenges for all groups were: staff too busy, staff shortages, lack of staff engagement, added workload of the bundle and patient coding issues. The participants shared facilitating factors used to overcome issues including: shifting perceptions to improve engagement, further education sessions to increase staff participation and gaining buy-in from managers through payment frameworks.

Conclusions: Maximising the impact of a care bundle relies on its successful and timely implementation. Teams implementing the COPD care bundle encountered challenges that were common to all teams and sites. Understanding and learning from the challenges faced by previous endeavours and identifying the facilitators to overcoming these barriers provides an opportunity to mitigate issues that waste time and resources, and ensures that training can be tailored to the anticipated challenges.

\section{INTRODUCTION}

Chronic obstructive pulmonary disease (COPD) remains a major health problem

\section{KEY MESSAGES}

With popularity of the concept of care bundles growing, the need for future implementation teams to be informed of the key challenges involved in implementing a care bundle is essential.

- Focus groups revealed that the five most significant challenges to successful implementation were: staff too busy, staff shortages, lack of staff engagement, added workload of the bundle and patient coding issues.

- Maximising the impact of a care bundle relies on its successful and timely implementation. A prior understanding of the challenges that teams may encounter provides an opportunity to mitigate these issues, saving time and resource and ensuring training tailored to the anticipated challenges.

associated with a high mortality and morbidity. ${ }^{1}$ Beginning in 2009, a COPD discharge care bundle was implemented across seven acute hospital sites in northwest London with support from the National Institute of Health Research (NIHR) Collaboration for Leadership in Applied Health Research and Care (CLAHRC) for Northwest London (NWL). The care bundle was implemented to address the recognised variation in clinical care of patients with acute exacerbation of COPD. ${ }^{1-5}$ Care bundles are a selection of four to five evidence-based practices that should be delivered to all patients, and have been demonstrated to be an effective tool for improving outcomes in patients with COPD. ${ }^{6-8}$

The COPD discharge care bundle included five evidence-based elements to be provided at discharge from hospital following an acute exacerbation of COPD. The five elements were:

- If the patient is a smoker, offer smoking cessation assistance;

- Refer for assessment for pulmonary rehabilitation; 
- Give written information about COPD including British Lung Foundation (BLF) self-management booklet, oxygen alert card and information about patient support groups (BLF Breathe Easy Group).

- Demonstrate satisfactory use of inhalers.

- Follow-up appointment to be made with a specialist prior to discharge.

The initial pilot study suggested that the 30-day readmission rate was $5.6 \%$ lower after initiation of the COPD care bundle, ${ }^{8}$ although the results were not statistically significant they provided sufficient evidence that further implementation would be beneficial to patients. Implementation first spread to other hospitals across London as part of a Commissioning for Quality and Innovation (CQUIN) payment framework, which makes a proportion of providers' income conditional on achieving targets. ${ }^{9}$ This study describes the implementation of the COPD care bundle across seven sites from September 2010 to April 2012. The retrospective analysis conducted within this study does not refer to data collected during the pilot study.

CLAHRCs were developed to accelerate the implementation of evidence into practice, addressing the disconnect between the development of new innovations and their implementation in routine clinical practice. ${ }^{10}$ NIHR CLAHRC for NWL employs a quality improvement collaborative approach, providing funding and support to front line healthcare teams to improve practice. As the teams implemented the COPD care bundles, CLAHRC NWL supported them by providing the tools for monitoring delivery of the bundle. The COPD care bundle implementation showed varied compliance patterns and delivery (table 1) with average compliance between sites ranging from $42.8 \%$ to $84.4 \%$ during the study period. Compliance was measured as the team's ability to deliver all elements of the care bundle ( $100 \%$ compliance $=$ all elements delivered) . Monthly compliance measures at individual site level also showed wide variability which indicated that although the COPD care bundle seemed simple in concept, it may not be implemented optimally in practice, a finding noted for care bundles in other settings. ${ }^{11}$

Care bundles have been shown to improve outcomes, reduce hospital readmissions and reduce length of hospital stay, ${ }^{71-13}$ therefore increasing the speed of uptake and delivery of fully compliant care bundles should be a priority in order to deliver more timely improvements and more consistent high-quality care. While previous studies have detailed the difficulties of obtaining full compliance to bundle elements, ${ }^{12}{ }^{14}{ }^{15}$ few have described the underlying reasons for this. In order to improve compliance with bundle elements and hasten uptake there is a need for detailed information on the experience of implementing bundles to be shared. This will provide necessary information on the context in which implementation of evidence takes place. ${ }^{16}$ To understand the context and experience of implementing a COPD care bundle, teams were consulted for their experience and perceptions. This study describes the challenges identified by improvement teams in delivering a COPD care bundle in practice and explores the actions taken by teams to overcome these issues.

\section{METHODS \\ Documentary analysis}

Implementation teams across all sites recorded a range of quantitative and qualitative data throughout the projects. The CLAHRC NWL approach supports the use of a number of quality improvement tools that allow the team to capture their data in a continuous and iterative fashion. The data were recorded using an online webbased reporting tool which is now called the Web Improvement Support in Healthcare (WISH) system. ${ }^{16}$ WISH allows teams to easily record their data and produce improvement measure reports using Statistical Process Control (SPC), enabling teams to identify when there are significant changes to their measures. Teams reviewed improvement measures that provided information on the progress of bundle implementation, including the number of patients who had received the bundle with compliance of bundle delivery reported as SPC run charts. The teams also recorded qualitative progress feedback using Plan-Do-Study-Act (PDSA) cycles $^{17}$ which provided a structure for teams to document their implementation plans, the successes and failures of these plans, and any changes they had made as a result. The teams provided structured reports at defined time points (6, 12 and 18 months) during their projects including the teams' reflections on the application of a range of

Table 1 Acute care organisation; hospital site and improvement team composition

\begin{tabular}{lllll}
\hline Acute care organisation & A & B & C & D \\
\hline Number of sites & 1 & 3 & 2 & 1 \\
Approximate number of beds & 429 & 1258 & 631 & Yes \\
Presence of emergency department & Yes & 8 & Yes & 10 \\
Number of bundle team members & Yes & 14 & Yes \\
Data used in documentary analysis & Yes (6) & Yes & Yes (5) & No \\
Team participated in focus groups (n) & 150 & 327 & 389 & Yes (6) \\
Total number of bundles delivered at time of study & Yes & Yes & Yes & Yes \\
Achieved CQUIN target & & &
\end{tabular}


quality improvement tools and techniques used for the implementation of the COPD care bundle. Documentary analysis of these data was performed by the CLAHRC NWL research team using Nvivo V.9, a qualitative data analysis software tool. The qualitative analysis was based on a thematic framework approach. ${ }^{18}$ Initial themes were identified from a small sample of source data and applied across the whole dataset to generate detailed examples of the themes.

As the skills of those delivering the interventions are important for successful implementation, ${ }^{19}$ an exercise was also conducted to identify how challenges found in the documentary analysis were related to the skills of the staff implementing the bundle. To do this, the range of knowledge and skills required for quality improvement identified by the Institute for Healthcare Improvement $(\mathrm{IHI})^{20}$ were combined with the Donabedian model for assessing healthcare quality to form a competency framework $^{21}$ (table 2).

\section{Focus groups}

All COPD care bundle implementation teams from northwest London were invited to participate in the focus groups. Researchers aimed to recruit between five and eight participants for each group as it has been found that this is an ideal size for non-commercial focus groups. ${ }^{22}$ These smaller groups allow for more in-depth discussion and make participants more comfortable to share their views. ${ }^{22}$ Three focus groups took place involving implementation team members from five of the seven hospital sites across northwest London. Seventeen healthcare professionals and healthcare managers participated in the three groups with group size ranging from five to six participants. The professional affiliation of participants for each focus group is shown in table 2 .

The focus groups provided an opportunity for the implementation teams to discuss and rank challenges identified by the initial documentary analysis as well as present further challenges not previously identified. A semistructured discussion followed where the teams discussed the solutions and facilitators that were developed during the project to overcome the challenges identified. The focus groups were facilitated by an independent researcher (LL or HM) who had not been involved in the implementation work. The sessions were audio recorded and an additional researcher made field notes during the focus groups.

The audio recording and field notes were imported into Nvivo 9 and analysed using thematic content analysis. ${ }^{23}$ The workshop data were categorised based on the thematic challenges and within these categories, solutions identified were deductively derived. Analysis was undertaken by two investigators to aid in the reliability of coding. The data from each focus group were analysed individually and then aggregated. Quotes from individuals were used to illustrate the themes arising collectively from the different sites.

\section{RESULTS}

Table 1 displays the characteristics of the hospital sites and improvement teams that participated in the study. Additional metrics have been provided to allow comparison between organisations and sites.

\section{Documentary analysis}

The documentary analysis uncovered a number of challenges identified by the teams. Five high level themes with 28 associated challenges were identified during the analysis (table 3 ).

\section{Focus groups}

The results from the documentary analysis were summarised to produce a competency table (table 4). This triangulation verified that the range of challenges encountered by teams were linked to skills and knowledge domains and related to quality improvement within health systems. This information was used to structure the focus group discussion.

The focus groups were shown the challenges identified in the documentary analysis and participants were given the opportunity to rank the high-level themes according to impact of the challenge. Although the group discussed all challenges identified in the documentary analysis, this section focuses on the findings for the five most significant challenges, as ranked by the focus groups. All focus groups identified staffing as the greatest high-level challenge to implementation (figure 1).

The five most significant challenges to bundle implementation were: staff too busy, staff shortages, lack of staff engagement, added workload of the bundle and patient coding issues. These challenges and their suggested solutions are summarised in table 5 .

Focus group participants reported that staffing issues had a negative impact on the uptake of the bundle. Staff perception was initially a major barrier to uptake of the bundle as many staff believed the bundle may be "just another piece of paper" (Nurse, group 1) that would result in extra work. Participants also commented that the bundle had an impact on their workload and was often seen as too time consuming, with one participant commenting that initially the nurses had to "stop what they were doing to do the bundle" (Clinical Nurse Specialist (CNS), group 2). These issues led to a lack of staff engagement resulting in eligible patients missing out on receiving all elements of the bundle.

One site found that presenting the bundle as best practice resulted in staff being more likely to engage with the project and more willing to complete the bundles. The response to the bundle was much more positive when the staff saw it as "simply a way of recording the activities they were already doing" (Consultant, group 1). Once the bundle had been positioned as best practice it was no longer considered extra work but as part of the standard of care required for all patients. "We are doing this anyways, we are just trying to make sure that everybody gets it and it is going to be part of 
Table 2 Professional affiliation of focus group partcipants

\begin{tabular}{llll}
\hline $\begin{array}{l}\text { Professional } \\
\text { affiliation }\end{array}$ & $\begin{array}{l}\text { Focus } \\
\text { group 1 }\end{array}$ & $\begin{array}{l}\text { Focus } \\
\text { group 2 }\end{array}$ & $\begin{array}{l}\text { Focus } \\
\text { group 3 }\end{array}$ \\
\hline $\begin{array}{l}\text { Consultant } \\
\text { Nurse/clinical nurse }\end{array}$ & 1 & 1 & 1 \\
specialist & 2 & 3 & 3 \\
$\begin{array}{l}\text { Physiotherapist } \\
\text { Pharmacist }\end{array}$ & 1 & 1 & - \\
$\begin{array}{l}\text { Project manager } \\
\text { Senior executive/ }\end{array}$ & 1 & - & - \\
manager & - & - & 1 \\
\hline
\end{tabular}

provding a better service to the patients" (Consultant, group 1).

Staff being too busy was consistently voted as a major challenge at all focus groups. Two teams identified the use of a multidisciplinary team as a facilitator. The teams found that having multiple professionals involved in the delivery of the bundle allowed the workload to be shared thus having less of an impact on one professional's responsibilities. This allowed the bundle to be completed more often and for fewer eligible patients to be missed. While staff shortages were identified as a significant challenge by all sites, teams did not identify or suggest any potential solutions for this area. It was often considered to be outside of the teams' control and therefore solutions were not considered possible. It was evident from the discussions that the staff group most likely to be impacted by shortages was nurses.

Having a CNS, designated bundle nurse or project champion on the team was also identified as being a key facilitator to staff engagement issues. Participants commented that having a bundle champion or CNS aided in "getting people on board" (Clinical lead, group 2) and motivating staff members to complete the bundles. One team stated that having a champion also allows for the project to be rolled out in new setting more smoothly as it allowed staff to learn from someone they already knew. "If you are going to do it, find a champion on the ward. Nurses do not respond to someone who comes on to the ward as much as they do to someone they already work with" (Consultant, group 3).

Participants also identified that having a CQUIN was a key contributor to the uptake of the project and staff engagement. Having a CQUIN in place improved use of the bundle and allowed the staff to see the financial importance of delivering the bundle. The CQUIN also played a key role in having mangers and senior staff

Table 3 Themes and associated challenges identified in documentary analysis

\begin{tabular}{|c|c|}
\hline High level themes & Associated challenges \\
\hline Staffing & $\begin{array}{l}\text { Staff shortages } \\
\text { High staff turnover } \\
\text { Training of staff on bundle implementation } \\
\text { Training of staff on inhaler technique and smoking cessation } \\
\text { Staff not following the whole patient journey } \\
\text { Capability to make COPD referral-A\&E nurse/doctor not referring to appropriate ward } \\
\text { Lack of staff engagement } \\
\text { Low buy in from pharmacists }\end{array}$ \\
\hline Infrastructure & $\begin{array}{l}\text { Added workload of bundle } \\
\text { Bed shortages } \\
\text { Ward moves } \\
\text { Lack of pulmonary rehabilitation service } \\
\text { Issues with government plans } \\
\text { GP involvement } \\
\text { Sustainability and costs of BLF booklet }\end{array}$ \\
\hline Process & $\begin{array}{l}\text { Lack of prompt data capture } \\
\text { Patient coding issues (correct disease diagnostic coding) } \\
\text { Lack of prompt feedback to staff on the progress of the project } \\
\text { Poor quality of spirometry } \\
\text { - Completion status unclear because of community bundle end point }\end{array}$ \\
\hline Methodology & $\begin{array}{l}\text { Issues using PDSA cycles } \\
\text { NHS sustainability tool-too generic not context specific } \\
\text { Unfamiliarity with tools }\end{array}$ \\
\hline Patient and public involvement & $\begin{array}{l}\text { Patient involvement declined over time } \\
\text { - Patients focused on own interest and not the projects' } \\
\text { - Patient illness } \\
\text { - Patient engagement poor }\end{array}$ \\
\hline
\end{tabular}

BLF, British Lung Foundation; COPD, chronic obstructive pulmonary disease; GP, general practitioner; PDSA, Plan-Do-Study-Act. 
Table 4 Challenges aligned to the IHI Quality Improvement Competency Framework

Donabedian model of quality

Practice-based learning and improvement competency

Domain

Structure (staffing/infrastructure)

Customer knowledge-patients

perspectives and needs

Variation and measurement-collection and analysis of data

Leading, following and making changes in

healthcare-demonstration of change

management skills

Developing new, locally useful knowledgedemonstrating development and use of

PDSA cycles/model for improvement

Systems-based practice competency

Healthcare as process/system-engaging all

patients in the healthcare system

Collaboration-networking, joint working and

sharing knowledge and ideas within and

across organisations and between similar

services

Social context and accountability-

understanding conditions from a social

perspective linking with health and social

care model
Effectively engaging patients in the implementation of the bundle

Connectedness of IT systems to collect data at the patient level

Engaging and training staff with the necessary skills for implementation and evaluation of complex interventions

Staff capacity to develop skills required for iterative design and feedback

Representativeness of patient involved and engaged

Engagement between care providers and third sector organisations

Range of issues affecting disease beyond the biomedical model of healthcare
Process (care processes/knowledge exchange)

Ensuring the COPD care bundle meets the needs of the patients

Accuracy and resource to collect data on care processes

Delivering required care processes to reduce variation

Understanding the connectivity between care processes

Capturing all patients eligible for intervention

Sharing information about patient care

Conflicting priorities between different health and social care organisations and third sector providers
Outcomes (clinical outcomes/ ustainable change)

Demonstrating the COPD care bundle improves outcomes aligned

to the needs of the patients

Linkage of process data and outcome data at a patient leve

Sustaining change

Linking data to behaviour change and demonstrating causal linkage

Demonstrating population level health benefits

Competition versus collaboration

Demonstrating and sustaining system wide changes

IHI, Institute for Healthcare Improvement; PDSA, Plan-Do-Study-Act. 


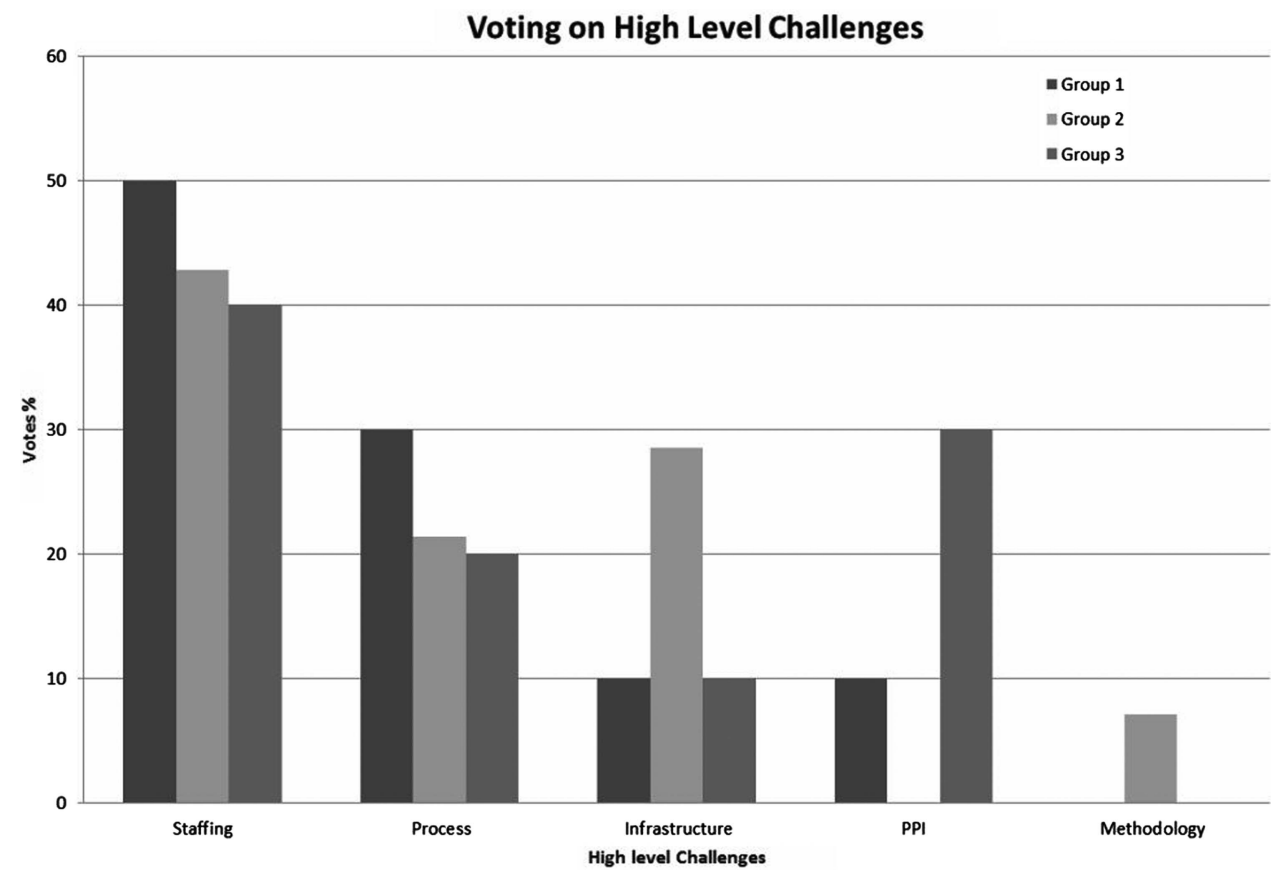

Figure 1 Focus group ranking of high-level themes Patient and Public Involvement (PPI).

involved in encouraging and supporting the implementation of the bundle. "When the CQUIN was introduced there were financial penalties for non-completion which meant managers were more interested in encouraging staff to complete the bundle" (Physiotherapist, group 1).

The only challenge that was ranked in the top five outside the staffing theme was patient diagnostic coding; which was identified as a significant challenge for all teams. Participants revealed that they had encountered major problems with erroneous data with one consultant commenting that " $50 \%$ of the data out of the warehouse are not COPD' because 'coding is reliant on many people in many systems" (Clinical lead, group 3). The issues related to patient coding resulted in eligible patients not receiving the bundle. Teams identified a range of solutions to address this challenge including performing baseline audits of patient coding to assess for coding accuracy, working with coders to understand the coding process, engaging coders in the project and educating junior doctors on coding processes.

\section{DISCUSSION}

The COPD care bundle has been designed to support the uniform implementation of best practice, providing a mechanism for delivering of evidence based care, while improving documentation and reducing variation of care processes. While care bundles have been shown to be effective in improving care processes and outcomes in a range of conditions and settings, challenges still remain in their effective design and implementation. ${ }^{12} 1324$ This is the first in-depth study to investigate staff perceptions of the challenges and facilitators of delivering a COPD care bundle. While this study provides a specific and focused overview of the challenges and potential facilitators associated with the implementation of a COPD care bundle in the acute hospital setting, the findings may be used by future teams to understand the potential challenges of implementing a bundle as well as ways to overcome them. The results of this study demonstrate a range of factors impacted the successful implementation of the COPD care bundle, which resonate with the findings from research in other studies of implementation. ${ }^{25-27}$ The solutions identified emphasise the need for ongoing support, education and engagement of staff as well as the importance of incentives to motivate staff and gain managerial buy-in.

Four of the five most significant challenges identified in this study relate to staffing, reflecting the importance of staff engagement and ensuring staff have the necessary skills and support to deliver improvements when implementing a care bundle. Highly engaged staff are associated with better outcomes and higher productivity and considered 'essential for making change and improvement happen'19 emphasising the need for early and consistent staff engagement throughout bundle projects. The role of 'adopter' has been identified in previous studies as integral to achieving success in implementation of evidence and innovations into practice. ${ }^{19} 2526$ This study further explored staff perceptions and their role as 'adopters' providing insight into how organisations may support staff to address potential issues and ensure maximum engagement during improvement initiatives. The challenges identified around patient coding highlight the need for robust coding measures to underpin the delivery of change and 
Table 5 Top 5 challenges and facilitators

\begin{tabular}{|c|c|c|c|}
\hline Challenge & Solution & Rationale & Focus group comments \\
\hline Staff too busy & Use of a multidisciplinary team & $\begin{array}{l}\text { Bundle initiated more consistently and less } \\
\text { impact on one person's workload }\end{array}$ & $\begin{array}{l}\text { "Having multidisciplinary people get involved helps with the } \\
\text { initiation of the bundle. Because even if one person misses it a } \\
\text { physio or nurse comes and starts it and even a pharmacist can } \\
\text { say this patient isn't on a bundle and start one" (Physiotherapist, } \\
\text { group 1) }\end{array}$ \\
\hline Staff shortages & None identified & Viewed as out of staff control & $\begin{array}{l}\text { "There are some things we will never have solutions for... } \\
\text { because we can't, we don't have any power over that" (Nurse, } \\
\text { group 2) }\end{array}$ \\
\hline Staff engagement & $\begin{array}{l}\text { Change perception of the } \\
\text { bundle from research to best } \\
\text { practice } \\
\text { Finding project champions } \\
\text { Having a CQUIN in place } \\
\text { Educating the staff on the } \\
\text { benefits of the bundle }\end{array}$ & $\begin{array}{l}\text { Demonstrated to staff that this should be } \\
\text { done for every patient regardless of the } \\
\text { bundle } \\
\text { Aided in getting people on board and } \\
\text { motivating staff to complete the bundle } \\
\text { Allowed the staff to see the financial } \\
\text { importance of bundle delivery and was key in } \\
\text { gaining support from managers } \\
\text { Allowed staff to recognise the improvement } \\
\text { the bundle makes to patient's care }\end{array}$ & $\begin{array}{l}\text { "It was about educating and changing the perceptions...that really } \\
\text { the two things we asked them to do, are what they should be } \\
\text { doing during their everyday work anyway like inhaler technique } \\
\text { and smoking cessation...So once the perception was changed } \\
\text { and actually it was part of their everyday role, they didn't see it as } \\
\text { an add-on to what they were already doing" (Nurse, group 1) } \\
\text { "If you are going to do it, find a champion on the ward. Nurses do } \\
\text { not respond to someone who comes on to the ward as much as } \\
\text { they do to someone they already work with" (Consultant, group 3) } \\
\text { "When the CQUIN was introduced there were financial penalties } \\
\text { for non-completion which meant managers were more interested } \\
\text { in encouraging staff to complete the bundle" (Physiotherapist, } \\
\text { group 2) } \\
\text { "If nurses don't understand something they are not going to do it. } \\
\text { The benefits of PR(Pulmonary rehab), inhaler technique, of } \\
\text { course they want to do it because they want to provide the best } \\
\text { care but if they don't understand it they aren't going to do it. If you } \\
\text { have someone there explaining than it is much better" (Clinical } \\
\text { Nurse Specialist, group 2) }\end{array}$ \\
\hline $\begin{array}{l}\text { Added workload } \\
\text { of the bundle }\end{array}$ & $\begin{array}{l}\text { Changing the perception of the } \\
\text { work involved in delivering the } \\
\text { bundle }\end{array}$ & $\begin{array}{l}\text { No longer considered extra work but as part } \\
\text { of the standard of care required for all } \\
\text { patients }\end{array}$ & $\begin{array}{l}\text { "A large part was changing the perception of the bundle, they } \\
\text { envisaged it as more time consuming than it actually was, } \\
\text { because they are constantly being given more paperwork around } \\
\text { various diseases and to them it was just another piece of paper } \\
\text { that they thought would be a lot of work" (Nurse, group 1) }\end{array}$ \\
\hline $\begin{array}{l}\text { Patient coding } \\
\text { issues }\end{array}$ & $\begin{array}{l}\text { Engaging coders in the project } \\
\text { Educating junior doctors on } \\
\text { coding technique }\end{array}$ & $\begin{array}{l}\text { Coders aware of the bundle project and able } \\
\text { to properly code patients } \\
\text { Eligible patient accurately coded and started } \\
\text { on the bundle }\end{array}$ & $\begin{array}{l}\text { "The team asked the coders to talk us through their process...by } \\
\text { understanding their process we were able to help them } \\
\text { understand ours" (Nurse, group 1) } \\
\text { "Making sure that education is paramount for junior doctors... so } \\
\text { that they are aware how to code the conditions" (Consultant, } \\
\text { group 2) }\end{array}$ \\
\hline
\end{tabular}


the need for clinicians to be adequately educated and confident that the patient diagnosis is correct and accurately recorded. Although coding issues continue to be long-standing concerns within hospitals, recent reports have demonstrated that overall the quality and accuracy of coding is improving. ${ }^{28} 29$

Importantly, this study also highlights facilitators and actions taken by staff during the implementation of the COPD care bundle. Implementation teams overcame many challenges by ensuring a multidisciplinary team structure in delivering elements of the COPD care bundle, for example, ward nurses offered smoking cessation referrals, physiotherapists assessed for pulmonary rehabilitation, and CNS advised on self-management. Fulbrook and Mooney ${ }^{27}$ found similar results in their study on the implementation of a care bundle in critical care and noted that "if ownership of the care bundle is widespread...its implementation is more likely to be successfully sustained." Different staff members played key roles in overcoming challenges throughout the projects. 'Bundle champions' encouraged staff engagement and changed staff perceptions, respiratory clinicians engaged clinical coding staff, and respiratory nurse specialists supported ward nurses, an important aspect of sustaining change.

Implementing bundles which achieve $100 \%$ compliance often involves prolonged periods of learning and adaption. ${ }^{11}$ Planning for this time is imperative and will help teams to set realistic goals and anticipate training needs. While all teams reported variable monthly compliance throughout the duration of the projects it is important to note that all teams did achieve 100\% compliance at specific points in time allowing each to meet their CQUIN targets. This variability demonstrates that while challenges are encountered, teams often require time and experience as well as ongoing support to address challenges and improve compliance over time.

With popularity of the concept of bundles growing, the need for future implementation teams to be informed of the key challenges involved in implementing a care bundle is essential. As bundles seem relatively simple in concept, there is a risk that future teams may begin new bundle projects or alter existing bundles without recognising the inherent challenges involved in delivering a care bundle and the potential impact it may have on staff and systems. ${ }^{30}$ This paper offers important lessons from frontline teams that have implemented the COPD care bundle and describes the challenges. The paper also provides information on facilitators used to mitigate these challenges which can be used to inform future implementation teams in overcoming similar barriers.

A potential limitation is the generalisability of the results as the thoughts and opinions collected from participants may not be representative of all staff involved in the implementation of the COPD care bundles however similar results are supported in the literature. ${ }^{11} 12 \quad 27$ These findings may not be applicable to care bundles in all other disease areas but reinforce that implementation of evidence into care is not without challenges which should be considered before implementation begins.

Maximising the impact of a care bundle relies on its successful and timely implementation. A priori understanding of the challenges that teams may encounter provides an opportunity to mitigate these issues, saving time and resource and ensuring training tailored to the anticipated challenges. Shared learning of the facilitators can also equip organisations with the knowledge of the importance of broader and effective stakeholder engagement early on in implementation efforts, ensuring the team have the knowledge and skills, and the perception of having sufficient time to ensure successful implementation. It has been recognised that there is a need to understand the mechanisms that make improvement projects work. ${ }^{16} 29$ This study provides invaluable information on what has made the COPD care bundle 'work' for teams looking to begin or improve their own bundle implementation. The findings from this study may allow future teams to establish early on the challenges associated with implementing care bundles and help teams to mitigate issues where possible, improving uptake and hastening implementation to deliver the best care possible faster.

Acknowledgements The authors would like to acknowledge the work undertaken to deliver the quality improvement initiative by the implementation teams at Chelsea and Westminster Hospitals Trust, Imperial College NHS Trust, West Middlesex Hospitals Trust and Northwest London Hospitals Trust. The authors would also like to thank Dilys Lai, Bobby Mann, Trish Winn and Nick Hopkinson for their contribution.

Contributors SE, LL and HM conceived the study. LL, HM and SG performed the documentary analysis. $\mathrm{LL}$ and $\mathrm{HM}$ undertook the focus groups. $\mathrm{LL}, \mathrm{SG}$, $\mathrm{HM}$ and $\mathrm{CH}$ wrote the first draft; all authors contributed to the revision of the manuscript.

Disclaimer This article presents independent research commissioned by the National Institute for Health Research (NIHR) under the Collaborations for Leadership in Applied Health Research and Care (CLAHRC) programme for North West London. The views expressed in this publication are those of the author(s) and not necessarily those of the NHS, the NIHR or the Department of Health.

Funding National Institute for Health Research (NIHR) Collaborations for Leadership in Applied Health Research and Care (CLAHRC).

\section{Competing interests None.}

Ethics approval Ethics approval was not required for this work as it is part of a service evaluation and improvement project. All participants were NHS staff and provided verbal consent for the recording of the focus groups and were informed that all data would be anonymised for publication.

Provenance and peer review Not commissioned; externally peer reviewed.

Data sharing statement No additional data are available.

Open Access This is an Open Access article distributed in accordance with the Creative Commons Attribution Non Commercial (CC BY-NC 4.0) license, which permits others to distribute, remix, adapt, build upon this work noncommercially, and license their derivative works on different terms, provided the original work is properly cited and the use is non-commercial. See: http:// creativecommons.org/licenses/by-nc/4.0/

\section{REFERENCES}

1. Buckingham R, Lowe D, Pursey N, et al. Report of the National Chronic Obstructive Pulmonary Disease Audit 2008: clinical audit of 
COPD exacerbations admitted to acute NHS units across the UK Lodnon, 2008:1-81.

2. British Thoracic Society. Ready for Home? 2010.

3. Institute of Medicine. Crossing the quality chasm a new health system for the 21st century. National Academies Press, 2001.

4. Department of Health. Report of the high level group on clinical effectiveness. London, 2007.

5. Right Care. The NHS Atlas of variation in healthcare reducing unwarranted variation to increase value and improve quality. London, 2011.

6. Resar R, Griffin FA, Haraden C, et al. Using care bundles to improve health care quality innovation series. Cambridge, 2012.

7. Winn T, Noone M, Buxton M. How a COPD care bundle is reducing readmissions. Health Serv J 2011; November.

8. Hopkinson NS, Englebretsen C, Cooley N, et al. Designing and implementing a COPD discharge care bundle. Thorax 2012;67:90-2.

9. NHS Institute for Innovation and Improvement. Commisioning for Quality and Innovation (CQUIN) payment framework. 2012 [cited 2012 Oct 25]. http://www.dh.gov.uk/en/Publicationsandstatistics/ Publications/PublicationsPolicyAndGuidance/DH_091443

10. Cooksey SD, Cooksey D. A review of UK health research funding a review of UK health research funding. London, 2006.

11. Hampton DC, Griffith D, Howard A. Evidence-based clinical improvement for mechanically ventilated patients. Rehabil Nurs 2003;30:160-5.

12. Crunden $\mathrm{E}$, Boyce $\mathrm{C}$, Woodman $\mathrm{H}$, et al. An evaluation of the impact of the ventilator care bundle. Nurs Crit Care 2005;10:242-6.

13. Koehler BE, Richter KM, Youngblood L, et al. Reduction of 30-day postdischarge hospital readmission or emergency department (ED) visit rates in high-risk elderly medical patients through delivery of a targeted care bundle. J Hosp Med 2009;4:211-18.

14. Bird D, Zambuto A, O'Donnell C, et al. Adherence to ventilator-associated pneumonia bundle and incidence of ventilator-associated pneumonia in the surgical intensive care unit. Arch Surg 2010;145:465-70.

15. DuBose JJ, Inaba K, Shiflett A, et al. Measurable outcomes of quality improvement in the trauma intensive care unit: the impact of a daily quality rounding checklist. $J$ Trauma 2008;64:22-7.

16. Curcin V, Woodcock T, Poots AJ, et al. Model-driven approach to data collection and reporting for quality improvement. J Biomed Inform. 2014;in press.
17. Langley GJ, Moen R, Nolan K. The improvement guide: a practical approach to enhancing organizational performance. San Francisco: Jossey-Bass Publishers, 1996.

18. Pope $\mathrm{C}$, Ziebland $\mathrm{S}$, Mays $\mathrm{N}$. Analysing qualitative data. BMJ 2000;320:5-7.

19. The Kings Fund. Leadership and engagement for improvement in the NHS-Together we can. London, 2012.

20. Batalden $\mathrm{P}$, Berwick D, Bisognano $\mathrm{M}$, et al. Knowledge domains for health professional students seeking competency in the continual improvement \& innovation of health care. Boston, 1998:1-2.

21. Donabedian A. The quality of care. How can it be assessed? JAMA 1998;260:1743-8

22. Krueger RA, Casey MA. Focus groups: a practical guide for applied research fourth edition. Thousand Oaks: Sage Publications Ltd, 2009:63-81.

23. Carol Grbich. Qualitative research in health: an introduction. St. Leonards: Allen and Unwin, 1999:233-4.

24. Barochia AV, Cui X, Vitberg D, et al. Bundled care for septic shock: an analysis of clinical trials. Crit Care Med 2012;38:668-78.

25. Greenhalgh T, Robert G, Macfarlane F, et al. Diffusion of innovations in service organizations: systematic review and recommendations. Milbank Q 2004:82:581-629.

26. Grol R, Grimshaw J. Research into practice I from best evidence to best practice: effective implementation of change in patients' care. Lancet 2003;362:1225-31.

27. Fulbrook P, Mooney S. Care bundles in critical care: a practical approach to evidence-based practice. Nurs Crit Care 2003;8:249-55.

28. Chan KS, Fowles JB, Weiner JP. Review: electronic health records and the reliability and validity of quality measures: a review of the literature. Med Care Res Rev 2010;67:503-27.

29. Burns EM, Rigby E, Mamidanna R, et al. Systematic review of discharge coding accuracy. J Public Health (Bangkok) 2012;34:138-48.

30. Mackay AJ, Donaldson GC, Patel ARC, et al. Usefulness of the chronic obstructive pulmonary disease assessment test to evaluate severity of COPD exacerbations. Am J Respir Crit Care Med 2012;185:1218-24. http://www.atsjournals.org/doi/abs/10.1164/rccm. 201110-18430C 